\title{
Osamu Otsuka. "The Hazaraspid Dynasty's Legendary Kayanid Ancestry: the Flowering of Persian Literature under the Patronage of Local Rulers in the Late Il-khanid Period"
}

\section{Denise Aigle}

\section{OpenEdition}

\section{Journals}

Édition électronique

URL : https://journals.openedition.org/abstractairanica/53691

DOI : 10.4000/abstractairanica. 53691

ISSN : 1961-960X

Éditeur :

CNRS (UMR 7528 Mondes iraniens et indiens), Éditions de l'IFRI

Référence électronique

Denise Aigle, « Osamu Otsuka. "The Hazaraspid Dynasty's Legendary Kayanid Ancestry: the Flowering of Persian Literature under the Patronage of Local Rulers in the Late II-khanid Period" ", Abstracta Iranica [En ligne], Volume 42-43 | 2021, document 16, mis en ligne le 30 décembre 2021, consulté le 13 décembre 2022. URL : http://journals.openedition.org/abstractairanica/53691 ; DOI : https://doi.org/ 10.4000/abstractairanica.53691

Ce document a été généré automatiquement le 13 décembre 2022.

Tous droits réservés 


\title{
Osamu Otsuka. "The Hazaraspid Dynasty's Legendary Kayanid
} Ancestry: the Flowering of Persian Literature under the Patronage of Local Rulers in the Late Il-khanid Period"

\author{
Denise Aigle
}

\section{RÉFÉRENCE}

Osamu Otsuka. “The Hazaraspid Dynasty's Legendary Kayanid Ancestry: the Flowering of Persian Literature under the Patronage of Local Rulers in the Late Il-khanid Period", Journal of Persianate Studies, vol. 12, 2019, p. 181-205.

1 Dans cet article, l'auteur analyse les sources littéraires persanes qui ont été écrites sous le patronage de Nușrat al-Dīn, le souverain de la dynastie des Hazarspides du Luristān oriental et méridional à la fin de la période ilkhanide. De sa capitale İdjadj, cette dynastie locale réussit à conserver son autonomie pendant plus de deux siècles et demi, de 550/1155 à 827/1424. İdjadj, la capitale des Hazaraspids, était déjà prospère à l'époque préislamique, comme en témoignent dans le voisinage de nombreux vestiges élamites. Nuṣrat al-Dīn Aḥmad b. Yūsuf-Shāh (r. 1296-1332) est présenté par le chroniqueur Shabānkarā'ì dans son Majma al-ansāb, comme le descendant des souverains Kayanides. On trouve des attestations semblables chez de nombreux historiens.

2 Osamu Otsuka retrace l'histoire de la dynastie à partir de l'arrivée de Hülegü en Iran. Par une habile politique envers les envahisseurs mongols, les Hazaraspids réussirent à 
maintenir leur autonomie par rapport au pouvoir ilkhanide. L'auteur dresse la liste des sources historiques qui apportent des informations politiques sur la dynastie (p. 186). Ibn Batțūṭa, qui passa deux fois à İdjadj en 1327 puis en 1347, dresse un portrait élogieux de Nușrat al-Dīn. Il le présente comme un roi d'une extrême piété qui aurait fait construire quatre-cent-soixante zāwiya dans son royaume.

Tout en étant un souverain loué pour son activité de fondateur d'édifices charitables où était distribuée de la nourriture, Nușrat al-Dīn suscita une production littéraire importante. Un grand nombre d'ouvrages lui sont dédiés. Sharaf Qazvīnī ( $\mathrm{m}$. ca. 1339-1340) semble avoir joué une place centrale dans l'activité littéraire rédigée pendant le règne de Nușrat al-Dīn. Il est l'auteur d'une histoire des rois préislamiques, d'un manuel de correspondances et d'un manuel de chancellerie. Néanmoins, ces ouvrages ne semblent pas avoir été commandités par le souverain. Osamu Otsuka dresse la liste des titres élogieux qui lui sont attribués par Sharaf Qazvīnī (p. 194). Ces titulatures montrent que Nuşrat al-Dīn était perçu comme un pieux souverain musulman héritier de l'époque préislamique.

4 J'ajouterai qu'il n'y a pas que dans les sources historiques que Nuṣrat al-Dīn est valorisé. Shams al-Dīn 'Abd al-Lațîf, le petit-fils de Rūzbihān Baqlī Shīrāzī, lui a dédié la biographie édifiante de son aïeul, le Rūh al-jinān. Outre la vie du saint homme de Chiraz, ce texte contient un ensemble de "conseils au prince » (nașịhat). Nuṣrat al-Dīn y est qualifié de "Sultan glorifié » (sulțān al-mu'azzam), «Juste du monde» ('ādil-i jahān) et "Héritier du royaume des Kayanides» (warith-i mulk-i Kayān). Shams al-Dīn 'Abd alLațîf espérait peut-être que Nuṣrat al-Dīn constituerait des biens de mainmorte en faveur du sanctuaire de Rūzbihān Baqlì à Chiraz, comme il l'avait fait dans le Luristān.

\section{AUTEURS}

\section{DENISE AIGLE}

UMR 8167 - Orient et Méditerranée 